\title{
Mycobacterium tuberculosis co-existence with humans: making an imprint on the macrophage $\mathrm{P}_{2} \mathrm{X}_{7}$ receptor gene?
}

Correspondence

Igor Mokrousov

imokrousov@mail.ru

or

igormokrousov@yahoo.com

Received 18 June 2007

Accepted 11 January 2008
Igor Mokrousov, ${ }^{1}$ Nadezhda Sapozhnikova ${ }^{2}$ and Olga Narvskaya ${ }^{1}$

${ }^{1}$ Laboratory of Molecular Microbiology, St Petersburg Pasteur Institute, St Petersburg 197101 , Russia

${ }^{2}$ Research Institute of Phthisiopulmonology, St Petersburg 193063, Russia

The development of tuberculosis (TB) infection in humans depends on the mycobacterial strain and the human host, and is multigenically controlled in both. ATP ligation of P2X $\mathrm{X}_{7}$ receptors expressed on human macrophages infected with mycobacteria induces cell death and subsequent loss of intracellular bacterial viability. This study analysed the allelic distribution of two single-nucleotide polymorphisms (SNPs) in the P2RX7 gene in the Slavic population of the St Petersburg area of Russia. Analysis of the $-762 \mathrm{C} / \mathrm{T} P 2 R X 7$ promoter SNP revealed no significant association between pulmonary TB patients and control subjects $\left(3 \times 2 \chi^{2}=3.2,1\right.$ d.f., $P=0.2)$. The $-762 \mathrm{C}$ allele was highly and almost equally represented in both groups in this study (68.2\% in patients and $69.3 \%$ in controls). This result differs strikingly from a Gambian study where this allele was found in only 7 and $12 \%$ of pulmonary TB patients and controls, respectively [Li, C. M., Campbell, S. J., Kumararatne, D. S., Bellamy, R., Ruwende, C., McAdam, K. P. W. J., Hill, A. V. S. \& Lammas, D. A. (2002). J Infect Dis 186, 1458-1462]. In contrast, the frequency of the C allele at position 1513 in exon 13 , resulting in a loss of $P 2 X_{7}$ function, was significantly higher among pulmonary TB patients in this study $(P=0.02)$. Thus, analysis of the $\mathrm{P} 2 \mathrm{X}_{7}$ receptor gene in the Russian Slavic population showed that the $1513 \mathrm{C}$ allele, acting dominantly, is a possible risk factor for clinical TB, whereas the $-762 P 2 R X 7$ polymorphism did not appear to be associated with human susceptibility to TB.

\section{INTRODUCTION}

Tuberculosis (TB) is a re-emerging disease spread epidemically in many parts of the world. TB is an ancient disease, although Mycobacterium tuberculosis has been introduced into various geographically and politically isolated populations at very different times, and it appears that there are ethnic/racial differences in human susceptibility to TB (Stead, 1997). The disease reached the coastal people of Africa only in about 1910, and black populations have higher rates of TB and are also more likely to develop the more fulminant forms of the disease (reviewed by Bellamy, 1998; Stead, 1997). In contrast, TB has been endemic in Europe for a much longer period, reaching epidemic proportions during the 18th and 19th centuries (Daniel, 2006; Murray, 2004). The onset of TB epidemics in Russia

Abbreviations: $\mathrm{Cl}$, confidence interval; HIV, human immunodeficiency virus; HWE, Hardy-Weinberg equilibrium; LD, linkage disequilibrium; OR, odds ratio; SNP, single-nucleotide polymorphism; TB, tuberculosis.

A table showing the results of stratification analysis for the -762 and 1513 genotypes and alleles is available as supplementary material with the online version of this paper. was delayed compared with central Europe, and mortality remained very high at the beginning of the 20th century at 400 per 100000 of the population (Lapina, 1970).

M. tuberculosis is a facultative intracellular pathogen, and macrophages act both as the principal reservoir of infection and as the primary effector cells regulating bacterial growth and viability. ATP ligation of $\mathrm{P} 2 \mathrm{X}_{7}$ receptors expressed on human macrophages that are infected with mycobacteria induces cell death and subsequent loss of intracellular bacterial viability. The ATP-mediated killing of mycobacteria by macrophages is independent of other mechanisms, linked to SCL11A1 (formerly NRAMP1), VDR, HLA, IL, MBL and some other human genes (reviewed by Bellamy, 1998, 2005;

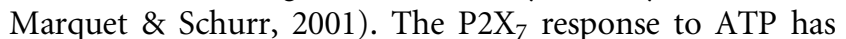
been shown to involve a calcium-dependent and phospholipase D-dependent effector pathway, which induces mycobacterial death via the promotion of phagosome-lysosome fusion (Fernando et al., 2007; Li et al., 2002).

The human P2RX7 gene encoding the $\mathrm{P}_{2} \mathrm{X}_{7}$ receptor comprises 13 exons localized on chromosome 12q24 (Buell et al., 1998). A homozygous $\mathrm{A} \rightarrow \mathrm{C}$ substitution in exon 13 at 
position 1513 is associated with loss of $\mathrm{P}_{2} \mathrm{X}_{7}$ function, whereas the heterozygous state results in cells with half the function of cells with the germline $\mathrm{P} 2 \mathrm{X}_{7}$ protein $(\mathrm{Gu}$ et al., 2001). Additionally, a protective association against TB in the Gambian population in West Africa has been found for a single-nucleotide polymorphism (SNP) at nucleotide position -762 in the putative P2RX7 promoter (Li et al., 2002).

This study is the first evaluation of the allelic distribution and possible link to susceptibility to TB of these two P2RX7 polymorphisms in the Russian Slavic population. We also compared our results with available data on these SNPs in other human populations.

\section{METHODS}

Sampling. A hundred and ninety human immunodeficiency virus (HIV)-negative pulmonary TB patients admitted to the hospital of the St Petersburg Research Institute of Phthisiopulmonology, Russia, were identified by M. tuberculosis culture. A total of 128 HIV-negative unrelated individuals, medical students or hospital staff, without a history of TB and autoimmune disease, were recruited as controls for this study. Both patient and control groups included only Russian Slavic individuals; this was determined for each individual by selfidentification. All persons gave their informed consent prior to inclusion in the study.

Genotyping. DNA was extracted from whole blood with a DNA Sorb B kit (AmpliSens). A PCR-RFLP assay was used to detect the A/C polymorphism at position 1513 in exon 13 in $P 2 R X 7$, as described previously (Li et al., 2002).

An allele-specific PCR assay was used to detect the C/T polymorphism at position -762 in $P 2 R X 7$ (position 1014 in GenBank accession no. Y12851) as follows. Two outer primers, P2X73 (5'-GAAACAGGGCCCTGGGTCCTC-3', forward) and P2X74 (5'-TGGTGGGGGTGGAGGGGC-3', reverse) flanked the entire region under study and amplified a $373 \mathrm{bp}$ fragment in all strains. Two allele-specific inner primers, P2X75 (5'-GGTGTCCCTCACTGAATAGGTCAAT-3', forward), and P2X76 (5'-GGCAGTCCAACAAAGTTAGGTTTG-3', reverse), were also used. For the $-762 \mathrm{C}$ allele, a 235 bp fragment was amplified using the outer forward (P2X73) and inner reverse (P2X76) primers. For the $-762 \mathrm{~T}$ allele, a $186 \mathrm{bp}$ fragment was amplified using the inner forward (P2X75) and outer reverse (P2X74) primers. Purified DNA $(1 \mu \mathrm{l})$ was added to the PCR mixture (final volume of $20 \mu \mathrm{l})$ containing $1.5 \mathrm{mM} \mathrm{MgCl}_{2}, 1 \mathrm{U}$ Taq DNA polymerase (Sileks), $100 \mu \mathrm{M}$ each dNTPs, and primers P2X73 and P2X76 (5 pmol each) and P2X74 and P2X75 (20 pmol each). The reaction was performed in a PTC-100 thermal controller (MJ Research) under the following conditions: initial denaturation at $96{ }^{\circ} \mathrm{C}$ for $3 \mathrm{~min}$; five cycles of $95{ }^{\circ} \mathrm{C}$ for $45 \mathrm{~s}, 68{ }^{\circ} \mathrm{C}$ for $1 \mathrm{~min}$ and $72{ }^{\circ} \mathrm{C}$ for $30 \mathrm{~s}$; five cycles of $95{ }^{\circ} \mathrm{C}$ for $40 \mathrm{~s}, 67^{\circ} \mathrm{C}$ for $50 \mathrm{~s}$ and $72{ }^{\circ} \mathrm{C}$ for $30 \mathrm{~s} ; 22$ cycles of $94{ }^{\circ} \mathrm{C}$ for $50 \mathrm{~s}, 66{ }^{\circ} \mathrm{C}$ for $40 \mathrm{~s}$ and $72{ }^{\circ} \mathrm{C}$ for $30 \mathrm{~s}$; and a final elongation at $72{ }^{\circ} \mathrm{C}$ for $3 \mathrm{~min}$. The amplified PCR fragments were subjected to electrophoresis in $1.5 \%$ standard agarose gels.

Statistical analysis. The existence of population subdivision among the case and control sets was tested using Wright's $F$ statistics according to the non-biased method of Weir and Cockerham $(\theta$ value; Weir \& Cockerham, 1984) using GDA software (Lewis \& Zaykin, 2001). Bootstrap tests (1000 replicates) were performed to determine results that were significantly different from 0 .

Genotype frequencies in each group were tested for correspondence to Hardy-Weinberg equilibrium (HWE). Linkage disequilibrium between the two SNPs was evaluated by calculating the normalized $\mathrm{D}^{\prime}$ measure of Lewontin (1964). The statistical significance ( $P$ value) of the pairwise disequilibrium was tested by excluding within-locus HWE. These analyses were carried out using GDA software (Lewis \& Zaykin, 2001) using 1000 runs.

Overall genotype frequencies in each patient group were compared using a $3 \times 2 \chi^{2}$ test with 2 degrees of freedom (d.f.). A $2 \times 2 \chi^{2}$ test was also used: (i) to detect any significant difference between the two groups in allele frequencies [Yates-corrected $\chi^{2}$ and $P$ values were calculated with a $95 \%$ confidence interval (CI)] and (ii) to test dominant and recessive models. This analysis was carried out using EpiCalc 2000 version 1.02 software (Gilman \& Myatt, 1998).

\section{RESULTS}

A total of $190 \mathrm{~TB}$ patients and 128 control subjects representing the Slavic population in the St Petersburg area of north-western Russia was included in this study. The mean age was 31.7 years (SD 11.1, range 15-70 years) for patients and 32.2 years (SD 12.0, range 21-71 years) for controls. The proportion of males was $47.7 \%$ in the control group and $64.7 \%$ in the patient group. Table 1 shows the results of genotyping of the two P2RX7 polymorphisms, $1513 \mathrm{~A} / \mathrm{C}$ and $-762 \mathrm{C} / \mathrm{T}$.

A subdivision analysis based on the two studied SNPs in $P 2 R X 7$ revealed no significant difference in the population structure between cases and controls. The Fst value (0.004) showed no significant departures from 0 (bootstrap of 1000 replicates), indicating an absence of genetic stratification among TB patients and controls in this study.

All genotypes in both loci were found to be in HWE (Table 1), although a slight under-representation of the -762 heterozygotes was noted in the control goup $\left(H_{\mathrm{obs}}=0.365\right.$ compared with $\left.H_{\mathrm{exp}}=0.429\right)$. The linkage disequilibrium (LD) analysis revealed the major alleles of the two loci to be in a weak $\mathrm{LD}\left(\mathrm{D}^{\prime}=-0.36, P=0.04\right)$ in the combined sample of the patient and control groups. Based on published recommendations (Ardlie et al., 2002; Tiret et al., 2002), we considered this LD not to be sufficient to influence a possible independent (non-)association of these two SNPs with TB.

Analysis of the $-762 P 2 R X 7$ promoter SNP revealed no significant difference in the genotype distribution in the two groups in our study using a $3 \times 2 \chi^{2}$ test $(P=0.2)$. The $-762 \mathrm{C}$ allele was both highly prevalent and almost equally represented $(68-69 \%)$ in both groups in our study $[2 \times 2$ $\chi^{2}=0.05$, odds ratio $(\mathrm{OR})=0.95(95 \%$ CI $0.67-1.34), 1$ d.f.; $P=0.8]$.

For the 1513 polymorphism, an overall difference in genotype distribution between the two groups was at borderline significance level $\left(3 \times 2 \chi^{2}=3.2\right.$, 2 d.f.; $\left.P=0.06\right)$. A closer look at the genotype distribution revealed that the wild-type AA homozygotes were significantly more prevalent in healthy controls $(P=0.02)$, whereas AC heterozygotes, in which half of the $\mathrm{P} 2 \mathrm{X}_{7}$ function was lost, were already significantly associated with the $\mathrm{TB}$ patient group $(P=0.05)$. Taken together, the frequency of the 1513C 
Table 1. Genotyping of SNP polymorphisms in the $P 2 R X 7$ gene in the Russian Slavic population

\begin{tabular}{|lccc|}
\hline SNP & No. of TB patients (\%) & No. of control subjects $(\%)$ & $P$ value \\
\hline Position 1513 & $120(63.8)$ & $96(76.2)$ & \\
AA & $59(31.4)$ & $27(21.4)$ & \\
AC & $9(4.8)$ & $3(2.4)$ & \\
CC & $188^{*}$ & $126^{*}$ & \\
Total & $77(20.5)$ & $33(13.1)$ & \\
C allele & 376 & 252 & \\
Total & 0.9 & 0.72 & \\
HWE $(P) \dagger$ & & $65(51.2)$ & \\
Position -762 & $86(45.3)$ & $46(36.2)$ & \\
CC & $87(45.8)$ & $16(12.6)$ & \\
CT & $17(8.9)$ & $127^{\star}$ & \\
TT & 190 & $176(69.3)$ & \\
Total & $259(68.2)$ & 254 & \\
C allele & 380 & 0.25 & \\
Total & 0.73 & & \\
HWE $(P) \dagger$ & & & \\
\hline
\end{tabular}

*There was some discrepancy between the total number of subjects and the number successfully analysed for each polymorphism due to failure of the PCR in some cases.

$\dagger \mathrm{HWE}(P)$ is the significance of correspondence to the Hardy-Weinberg proportions according to Pearson's $\chi^{2}$ test.

mutant allele was significantly higher in the TB patient group compared with the control subjects [Table $1 ; 2 \times 2$ $\chi^{2}=5.2$, OR 1.71 (95\% CI 1.10-2.66), 1 d.f.; $\left.P=0.02\right]$.

The effect of the $P 2 R X 7$ gene variants was assessed using both recessive and dominant models. This revealed that the overall OR for the 1513C deleterious allele as a risk factor was 1.81 (95\% CI 1.09-3.01, $P=0.03$ ) under a dominant model and 2.06 (95\% CI 0.55-7.77, $P=0.4$ ) under a recessive model. Testing of alleles in the -762 position revealed no statistical significance of either dominant or recessive model ( $P=0.3$ in both cases).

The frequency data of the two SNPs were further compared by stratification of the studied groups by sex or age, or, for patients, by diagnosis. This comparison revealed no significant difference in the -762 and 1513 genotypes and alleles (see Supplementary Table S1, available in JMM Online, for detailed information).

\section{DISCUSSION}

This study was undertaken to gain insight into the role of the human $\mathrm{P} 2 \mathrm{X}_{7}$ receptor gene in host susceptibility to TB in the Russian Slavic population. Areas of inflamed tissue such as TB granulomata contain numerous monocytes and macrophages, and high local concentrations of ATP (released from dying and activated cells) and proinflammatory cytokines (Solini et al., 1999). It is therefore possible that the ATP-linked $\mathrm{P}_{2} \mathrm{X}_{7}$ effector pathway may indeed contribute to host immunity to M. tuberculosis.

We found that the P2RX7 1513C allele was associated with an increased risk of pulmonary TB in Russians (Table 1).
This is not unexpected in view of the available knowledge of the role of this $\mathrm{P} 2 \mathrm{X}_{7}$ mutation in clinical development of TB in West Africans ( $\mathrm{Li}$ et al., 2002) and the Australian Vietnamese population (Fernando et al., 2007), although the latter study found an association with extrapulmonary rather than pulmonary TB. A role of selection in the population frequency differences of this allele is possible but is not clear at this stage. In the Russian setting, testing of dominant versus recessive models for the major allele 1513A revealed a statistical significance for the recessive model. In fact, this implies a dominant model for the minor, mutant allele $1513 \mathrm{C}$, for which deleterious action is manifested even in the heterozygous state.

No data have been published yet on the -762 P2RX7 SNP from areas of the world other than West Africa. A casecontrol study of the Gambian population showed that the $-762 \mathrm{CC}$ genotype was found more frequently in controls $(P=0.03)$, whilst the $-762 \mathrm{C}$ allele appeared to be associated with a protective effect against TB $(P=0.003$; Li et al., 2002). In the Gambia, the $C$ allele was found in 32.9 vs $25.4 \%$ and the CC genotype in only 12.7 vs $7.1 \%$ of controls and TB patients, respectively. In contrast, the Russian Slavic population showed much higher frequencies of both the $-762 \mathrm{C}$ 'protective' allele and CC homozygotes in both TB patients and controls groups (Table 1); the reason, albeit speculative, may lie in selection unrelated to $\mathrm{TB}$ and acting on this locus or another in LD with it. The sixfold difference in the frequency of the $-762 \mathrm{C}$ allele in the Russian and Gambian populations is striking and goes far beyond a genome variation observed among human populations. Thus, it appears that variation in the -762 position is not linked to human susceptibility to $\mathrm{TB}$, at 
least in Caucasians, although further studies in other settings are required.

In conclusion, analysis of these two SNPs in the P2RX7 gene in the Russian Slavic population showed that the P2RX7 1513 polymorphism is probably associated with host control of M. tuberculosis infection. The 1513C allele, acting dominantly, is a possible risk factor for clinical TB, whereas the $-762 \mathrm{C} / \mathrm{T} P 2 R X 7$ polymorphism does not appear to be associated with human susceptibility to TB.

\section{ACKNOWLEDGEMENTS}

We thank Tatiana Otten, Boris Vishnevsky, Asmik Asatryan, Elena Poretskova for help in obtaining some of the study samples and two anonymous reviewers for helpful comments.

\section{REFERENCES}

Ardlie, K. G., Kruglyak, L. \& Seielstad, M. (2002). Patterns of linkage disequilibrium in the human genome. Nat Rev Genet 3, 299-309.

Bellamy, R. (1998). Genetic susceptibility to tuberculosis in human populations. Thorax 53, 588-593.

Bellamy, R. (2005). Genetic susceptibility to tuberculosis. Clin Chest Med 26, 233-246.

Buell, G. N., Talabot, F., Gos, A., Lorenz, J., Lai, E., Morris, M. A. \& Antonarakis, S. E. (1998). Gene structure and chromosomal localization of the human $\mathrm{P} 2 \mathrm{X} 7$ receptor. Receptors Channels 5, 347-354.

Daniel, T. M. (2006). The history of tuberculosis. Respir Med 100, 1862-1870.

Fernando, S. L., Saunders, B. M., Sluyter, R., Skarratt, K. K., Goldberg, H., Marks, G. B., Wiley, J. S. \& Britton, W. J. (2007). A polymorphism in the $P 2 X 7$ gene increases susceptibility to extrapulmonary tuberculosis. Am J Respir Crit Care Med 175, 360-366.
Gilman, J. \& Myatt, M. (1998). EpiCalc 2000, version 1.02. London, UK: Brixton Books.

Gu, B. J., Zhang, W., Worthington, R. A., Sluyter, R., Dao-Ung, P., Petrou, S., Barden, J. A. \& Wiley, J. S. (2001). A Glu-496 to Ala polymorphism leads to loss of function of the human $\mathrm{P}_{2} \mathrm{X}_{7}$ receptor. J Biol Chem 276, 11135-11142.

Lapina, A. I. (1970). The development of tuberculosis control in the USSR. Bull Int Union Tuberc 43, 188-192.

Lewis, P. O. \& Zaykin, D. (2001). Genetic Data Analysis: computer program for the analysis of allelic data. Version 1.0. http:// www.eeb.uconn.edu/people/plewis/software.php

Lewontin, R. C. (1964). The interaction of selection and linkage. I. General considerations; heterotic models. Genetics 49, 49-67.

Li, C. M., Campbell, S. J., Kumararatne, D. S., Bellamy, R., Ruwende, C., McAdam, K. P. W. J., Hill, A. V. S. \& Lammas, D. A. (2002). Association of a polymorphism in the $\mathrm{P}_{2} \mathrm{X}_{7}$ gene with tuberculosis in a Gambian population. J Infect Dis 186, 1458-1462.

Marquet, S. \& Schurr, E. (2001). Genetics of susceptibility to infectious diseases: tuberculosis and leprosy as examples. Drug Metab Dispos 29, 479-483.

Murray, J. F. (2004). A century of tuberculosis. Am J Respir Crit Care Med 169, 1181-1186.

Solini, A., Chiozzi, P., Morelli, A., Fellin, R. \& Di Virgilio, F. (1999). Human primary fibroblasts in vitro express a purinergic P2X7 receptor coupled to ion fluxes, microvesicle formation and IL-6 release. J Cell Sci 112, 297-305.

Stead, W. W. (1997). The origin and erratic global spread of tuberculosis. How the past explains the present and is the key to the future. Clin Chest Med 18, 65-77.

Tiret, L., Pourier, O., Nicaud, V., Barbaux, S., Herrmann, S. M., Perret, C., Raoux, S., Francomme, C., Lebard, G. \& other authors (2002). Heterogeneity of linkage disequilibrium in human genes has implications for association studies of common diseases. Hum Mol Genet 11, 419-429.

Weir, B. S. \& Cockerham, C. C. (1984). Estimating F-statistics for the analysis of population structure. Evolution 38, 1358-1370. 